\title{
Shallow repeating seismic events under an alpine glacier at Mount Rainier, Washington, USA
}

\author{
Weston A. THELEN, ${ }^{1 *}$ Kate ALLSTADT, ${ }^{2}$ Silvio DE ANGELIS, ${ }^{2 \dagger}$ Stephen D. MALONE, ${ }^{2}$ \\ Seth C. MORAN, ${ }^{1}$ John VIDALE ${ }^{2}$ \\ ${ }^{1}$ Cascade Volcano Observatory, Vancouver, WA, USA \\ E-mail: wthelen@usgs.gov \\ ${ }^{2}$ Pacific Northwest Seismic Network, Department of Earth and Space Sciences, University of Washington, Seattle, WA, USA
}

\begin{abstract}
We observed several swarms of repeating low-frequency $(1-5 \mathrm{~Hz})$ seismic events during a 3 week period in May-June 2010, near the summit of Mount Rainier, Washington, USA, that likely were a result of stick-slip motion at the base of alpine glaciers. The dominant set of repeating events ('multiplets') featured $>4000$ individual events and did not exhibit daytime variations in recurrence interval or amplitude. Volcanoes and glaciers around the world are known to produce seismic signals with great variability in both frequency content and size. The low-frequency character and periodic recurrence of the Mount Rainier multiplets mimic long-period seismicity often seen at volcanoes, particularly during periods of unrest. However, their near-surface location, lack of common spectral peaks across the recording network, rapid attenuation of amplitudes with distance, and temporal correlation with weather systems all indicate that ice-related source mechanisms are the most likely explanation. We interpret the low-frequency character of these multiplets to be the result of trapping of seismic energy under glacial ice as it propagates through the highly heterogeneous and attenuating volcanic material. The Mount Rainier multiplet sequences underscore the difficulties in differentiating low-frequency signals due to glacial processes from those caused by volcanic processes on glacier-clad volcanoes.
\end{abstract}

\section{INTRODUCTION}

A fundamental goal of volcano monitoring is to assess whether particular seismic signals represent evidence of forthcoming eruptions. A wide range of seismic signals are recorded in volcanic environments, many unrelated to magma movement. Besides wind noise, debris flows/lahars, avalanches and rockfalls, glaciers are a particularly troublesome seismic source on some volcanoes from a volcanic hazard perspective (Weaver and Malone, 1979). Seismicity produced at or near the surface of glaciers, such as crevasse opening, serac collapse, basal slip or snow avalanches, can mimic signals that are commonly observed in association with fluid or gas transport within volcanoes (West and others, 2010). These signals are usually weak and generally only recorded at seismic stations close to the source (Weaver and Malone, 1976). However, there are many well-documented examples of glacier events generating large seismic signals recorded at considerable distance from their source (e.g. Wolf and others, 1997; Caplan-Auerbach and Huggel, 2007; Walter and others, 2008). Such events are usually attributed to either basal sliding or calving, and in extreme cases can produce earthquakes as large as magnitude 5 (Ekström and others, 2003).

Seismic events associated with glaciers, and shallow lowfrequency earthquakes associated with volcanic activity can produce similar waveforms (Weaver and Malone, 1976; West and others, 2010). The ability to distinguish between such sources is critical for providing correct interpretations of seismicity at glacier-clad volcanoes. In most cases, the

*Present address: Hawaiian Volcano Observatory, US Geological Survey (USGS), Hawaii National Park, HI, USA.

'Present address: Geophysical Institute, University of Alaska Fairbanks, Fairbanks, AK, USA. low-frequency content in glacial seismic signals is due to strong attenuation of high frequencies between the source and the recording station (Weaver and Malone, 1979; Métaxian and others, 2003) and/or longer-duration slip proportional to size (Ekström and others, 2003). Conversely, low-frequency earthquakes related to volcanic activity radiate primarily low-frequency energy from volumetric sources such as resonant fluid-filled fractures (e.g. Chouet, 1996). In this paper, we examine several sequences of repeating low-frequency earthquakes, referred to as multiplets, recorded on Mount Rainier, Washington, USA, during May-June 2010. We propose that these events are of glacial rather than volcanic origin.

\section{MOUNT RAINIER}

Mount Rainier has a greater volume of glacial ice on its flanks than any other mountain in the conterminous United States (Driedger and Kennard, 1986; Hoblitt and others, 1995). It also has the largest at-risk population of any volcano in the United States (Ewert and others, 2005). In part because of nearby population centers, the International Association of Volcanology and Chemistry of the Earth's Interior declared Mount Rainier a 'decade volcano' in 1989 to encourage research into the hazards that it poses to the local communities (Swanson and others, 1992). Mount Rainier's most recent eruptions occurred $\sim 1 \mathrm{kaBP}$, and $\sim 0.5$ ka BP a lahar, caused by a sector collapse, reached the Puget Lowlands (Sisson and Vallance, 2009).

Seismic monitoring at Mount Rainier dates back to 1962 when a World-Wide Standard Seismographic Network (WWSSN) station was installed on the lower slopes of the mountain. Currently Mount Rainier is monitored by the Pacific Northwest Seismic Network (PNSN) and the US Geological Survey's (USGS) Cascades Volcano Observatory 


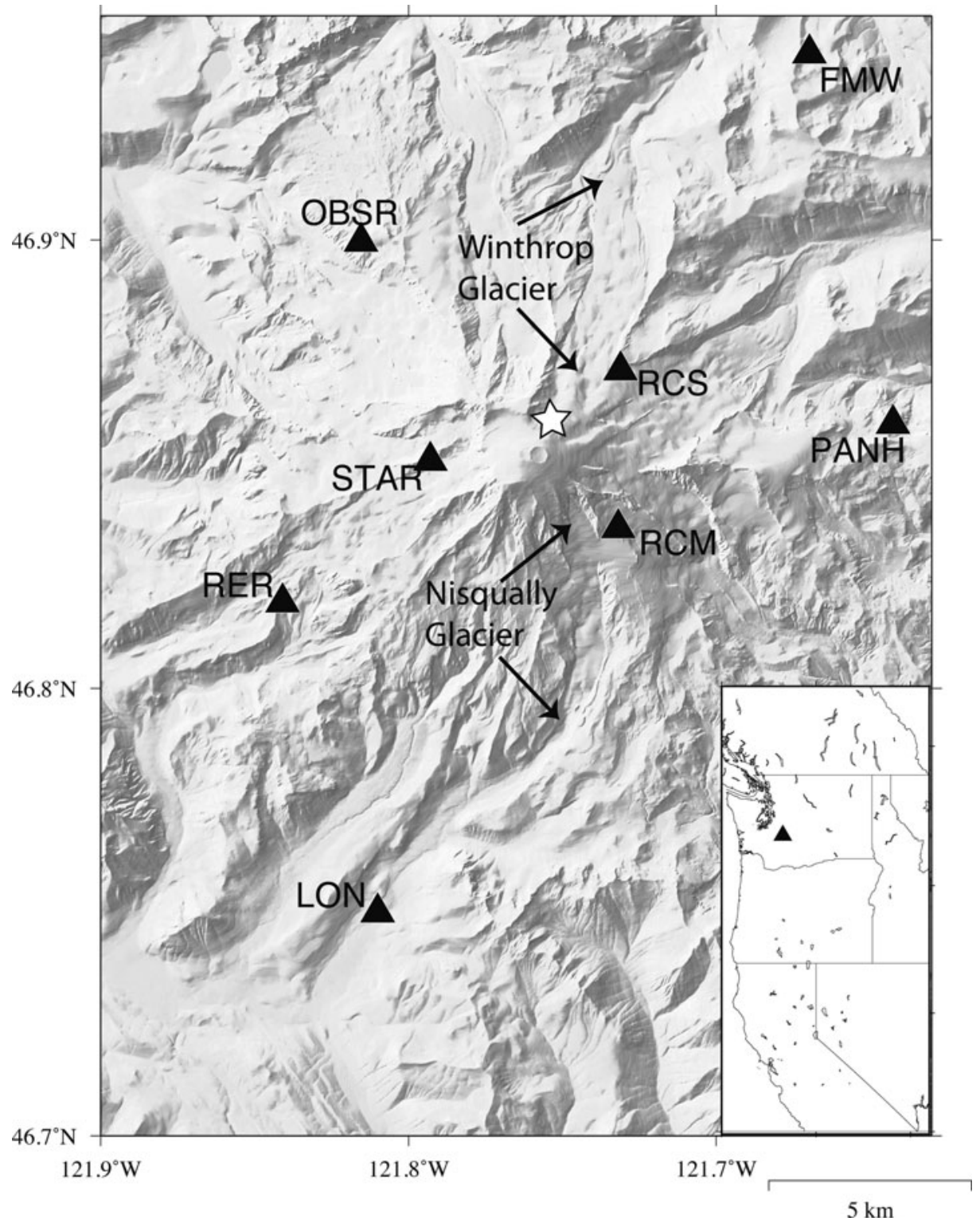

Fig. 1. Seismic station locations (triangles) and location of main multiplet of 2010 seismic sequence (star). RCM indicates the location of the Camp Muir seismic station and weather station. LON and LO2 seismometers are co-located.

via a network of eight real-time seismic stations within $15 \mathrm{~km}$ of the summit (Fig. 1). The seismic network around Mount Rainier is a mix of short-period stations $(1-2 \mathrm{~Hz}$ corner frequency; stations RCS, RCM, STAR, RER, FMW, LO2) and broadband instruments (40 s corner frequency or greater; stations PANH, OBSR, LON). This network has recorded a wide variety of seismic signals (Fig. 2). Ordinary volcano-tectonic (VT) earthquakes occur routinely, with a background rate of several per month (Moran and others, 2000). Many other seismic signals are readily interpreted using signal character, correlation with direct observations (e.g. rockfalls and avalanches) or by analogy with studies of similar events at other volcanoes (e.g. deep long-period earthquakes, VT earthquakes, glacial events).

Weaver and Malone (1979) conducted seismic experiments at several Cascade volcanoes and demonstrated that most low-frequency events at Mount Rainier have a glacial origin. They found that several distinctive features of glacial seismic sources, including low-frequency character and poor signal-to-noise ratios on stations off the volcanic edifice, are a result of strong path effects along the ice/rock interface. Subsequent studies at other glacially clad volcanoes have made similar conclusions (e.g. Métaxian and others, 2003), but do not address repeating low-frequency earthquakes such as we observed in the spring of 2010. Indeed, many low-frequency events at Mount Rainier are commonly recorded by just a single edifice station. Several exceptions to this occurred in 1990, 1992 and 1998, when sequences of similar events with regular recurrence intervals were recognized on several stations by the PNSN. These sequences lasted from days to weeks.

\section{REPEATING SEISMIC EVENTS AT MOUNT RAINIER, MAY-JUNE 2010}

The overwhelming majority of low-frequency seismic events at Mount Rainier are small and are not detected or located as part of routine processing by the PNSN. Daily visual inspections of continuous data are therefore also performed to find any events of significance not detected by the automated PNSN triggering system. In May 2010 a sequence of small low-frequency events was noted during daily 

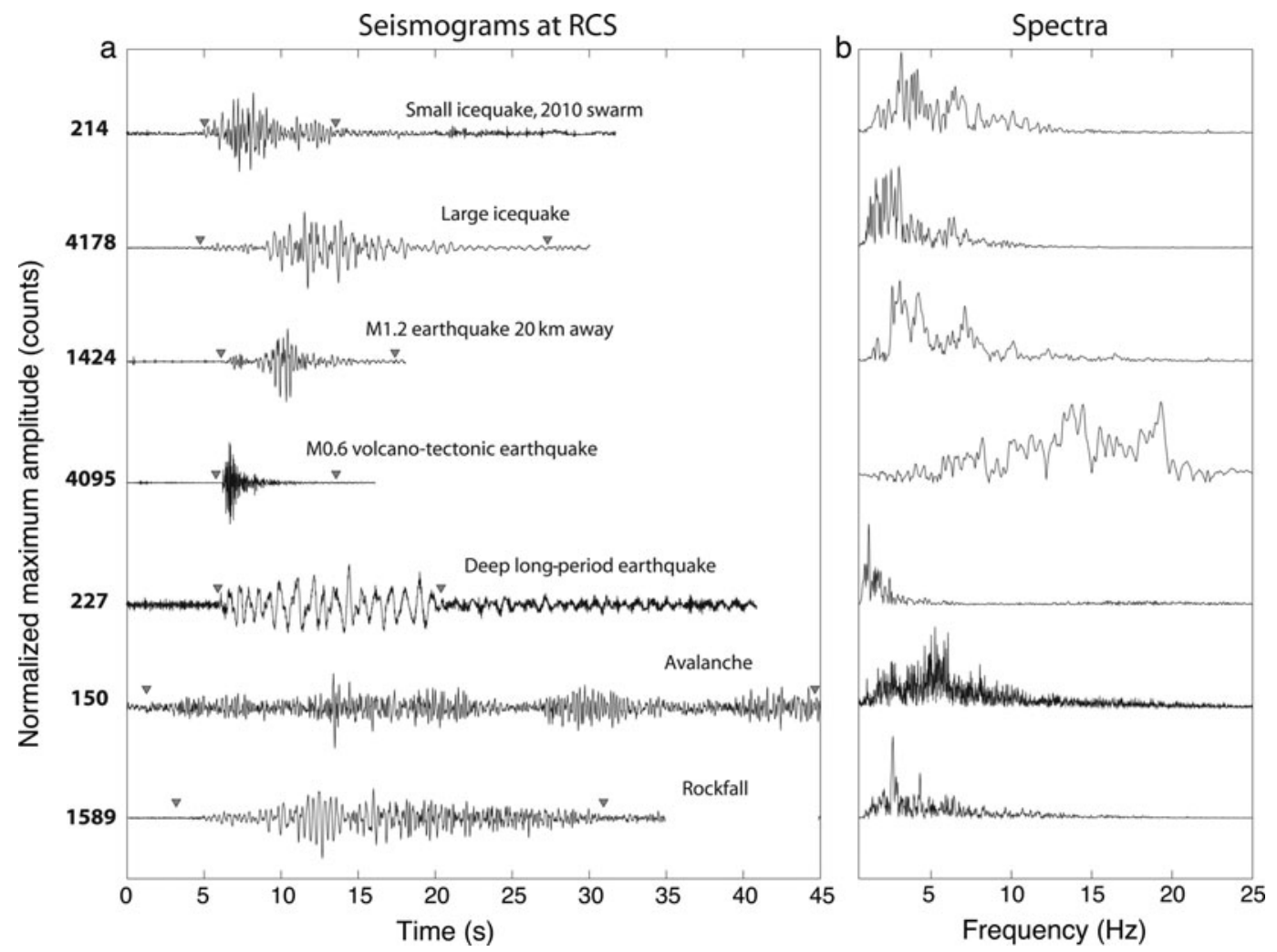

Fig. 2. Example of various types of waveforms (a) and their spectra (b) recorded on Mount Rainier at short-period vertical station RCS. The amplitude scale is normalized for each waveform, with the maximum amplitudes for each waveform given in counts on the left. Gray triangles indicate time windows for spectra. In order from the top of the plot: glacial earthquake, multiplet 5 of this sequence; inferred icequake; M1.2 tectonic earthquake located $\sim 20 \mathrm{~km}$ east of Mount Rainier; M0.6 volcano-tectonic earthquake located $2.5 \mathrm{~km}$ below the mountain from a September 2009 swarm; M2.3 deep long-period earthquake $13.6 \mathrm{~km}$ below Mount Rainier; avalanche on 5 June 2010 ; inferred rockfall near Willis Wall 7 June 2010.

inspections of seismic records. These events were mostly too small to trigger the PNSN-USGS network, but were recorded on several (up to six) near-summit stations. We rapidly determined that the events had similar waveforms by means of a methodology originally developed by Thelen and others $(2008,2010)$ described in detail in Section 3.1. Since similar sequences had been observed in 1990, 1992 and 1998 at Mount Rainier without any associated volcanic activity, and since the events had characteristics of glacially derived sources (Fig. 2), we were reasonably confident that these repeating events, or 'multiplets', were not related to volcanic unrest. The number of events per day gradually declined through the end of May, and then rapidly increased on 3 June following a significant precipitation event. The multiplet sequences continued through 10 June.

Multiplets are a ubiquitous feature of seismicity at many volcanoes, particularly in association with eruptions (e.g. Frémont and Malone, 1987; Lesage and Surono, 1995; Ratdomopurbo and Poupinet, 1995; Petersen, 2007; Luckett and others, 2008; Thelen and others, 2008, 2010), while a number of studies have investigated multiplets generated by glaciers (e.g. Danesi and others, 2007; Roux and others, 2008; Walter and others, 2008). It is when these two sources of multiplets are collocated at ice-clad volcanoes that it becomes difficult or impossible, yet critical, to differentiate between them. To our knowledge, the only other instances of multiplets at a glacier-clad volcano being inferred to have a glacial origin were at Katla volcano, Iceland (Jónsdóttir and others, 2009), and Mount Baker, Washington (CaplanAuerbach and others, 2009; Moran and others, 2009).

\subsection{Multiplet analysis}

In order to systematically analyze the Mount Rainier multiplets, we first screened the continuous data for all Mount Rainier stations using an event-detection algorithm based on a short-term average/long-term average (STA/LTA) ratio-based trigger (Allen, 1978). Data were bandpass-filtered between 1 and $10 \mathrm{~Hz}$ before analyzing for triggers. We used STA and LTA windows of 0.8 and $7 \mathrm{~s}$, respectively, and a single-station trigger was declared if the STA/LTA ratio of the signal envelope was $>2.5$. An event was declared if there were triggers on three of the four edifice stations (RCS, RCM, STAR, RER; Fig. 1) within $4 \mathrm{~s}$ of each other. These STA/LTA parameters were chosen empirically to best detect all events present during the study period. We then used the crosscorrelation method of Thelen and others (2010) to search for multiplets. The method requires waveform similarity between two events on multiple stations (but not between stations). We used a $9 \mathrm{~s}$ window starting $2 \mathrm{~s}$ before each automatic trigger for the comparison, and required a crosscorrelation coefficient (CCC) of at least 0.7 on two out of four stations (RCS, RCM, STAR, RER) for an event pair to be declared a multiplet. We chose a CCC of 0.7 because it was the lowest value for which the similarity between waveforms could be confirmed by eye. We chose a $9 \mathrm{~s}$ window for our similarity analysis because it encompasses the dominant duration of the events of interest. Using a long window for correlation also improves the quality of our similarity analysis. Shorter windows produced multiplets with greater variability, and longer windows degraded the resulting CCC. Requiring similarity on more than one station reduced the 
a

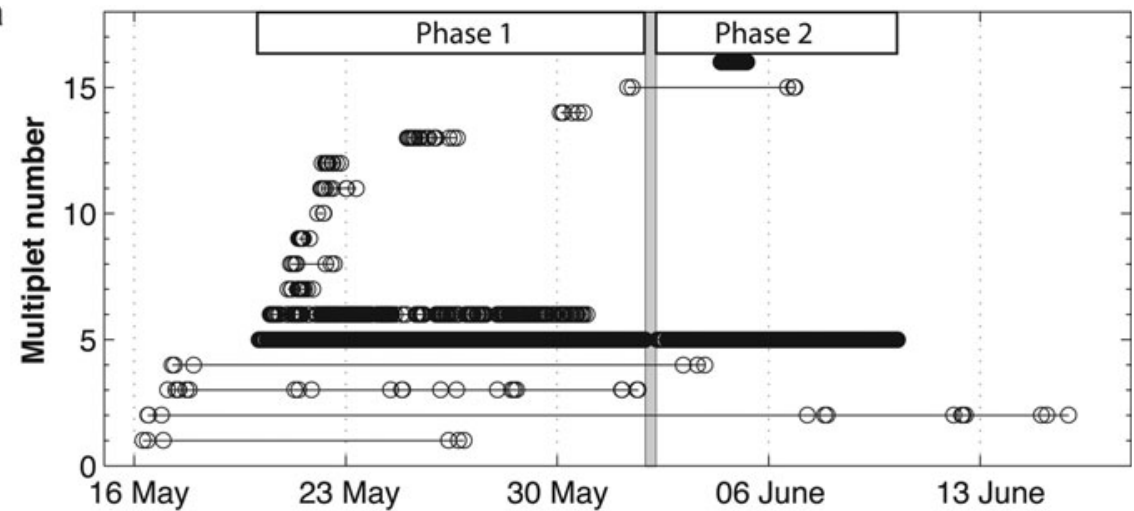

b

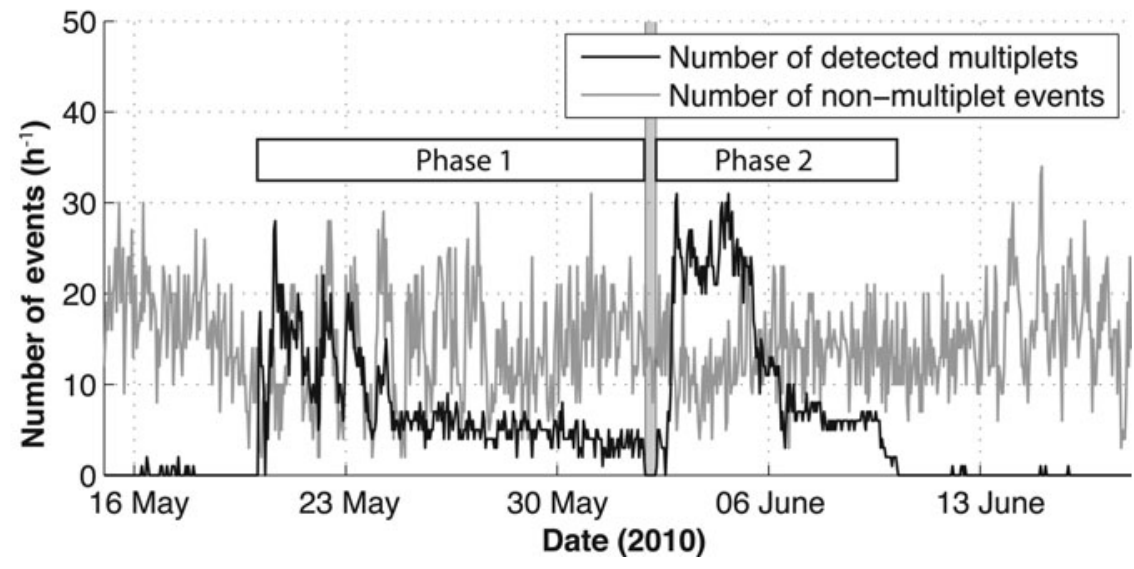

Fig. 3. (a) Timeline of multiplet occurrence, 15 May-18 June 2010. Each circle represents an earthquake; earthquakes on the same line are part of the same multiplet. Only multiplets with five or more events are shown. Gray rectangle shows the period when no multiplets occurred. (b) Comparison of number of detected non-multiplet events (gray line) to detected multiplets calculated every hour (black line). Gray rectangle shows the period when no multiplets occurred.

number of misidentified events, although small events that record well on a single station may be rejected as a result. Using two stations gave us the lowest number of misidentified events, while including events that may not be big enough to record on the entire network. Visual inspection of the results confirmed that the identified multiplets were distinct.

With nearly 17000 detected events between 16 May and 13 June, comparing each event independently to every other event would be too computationally expensive. To reduce computing load, events within a given day were organized into similar events (multiplets) and then stacked. Stacks were compared from each day, and similar stacks were combined if they met a 0.75 CCC threshold. A slightly larger CCC was used in order to preserve similarity within the multiplets at a level similar to the day-long analysis.

\subsection{May-June 2010 multiplets}

Fundamental earthquake parameters such as epicenter, depth and size can aid in the differentiation of volcanic and glacial sources. For example, earthquakes occurring at depth, or in areas where no glacier exists, cannot possibly be of glacial origin. In cases where the earthquake epicenters coincide with a glacier and the depths are clearly near the surface, other time-dependent parameters may be useful in delineating glacial sources from shallow volcanic hydrothermal sources, particularly when comparing to other temporal datasets. Here we describe basic earthquake parameters such as hypocenter, amplitude evolution, wave- form evolution and inter-event time in order to aid in our seismic source interpretation.

The 2010 multiplets occurred during two pulses of elevated seismicity across a 3 week period (Fig. 3). The first pulse began on 16 May with a handful of minor multiplets, then rapidly intensified on 20 May with the onset of the two most dominant multiplets (multiplets 5 and 6; Fig. 4) of the entire sequence, along with 14 other minor and short-lived multiplets (Fig. 3). After peaking around 23 May, seismicity rates across all multiplets gradually declined, eventually ceasing during a brief $\sim 10$ hour long hiatus late on 1 June (Fig. 3b). On 2 June the second pulse began with an abrupt onset that was dominated by events from multiplet 5, with multiplet 6 ceasing at the end of the first pulse. Multiplet rates remained at constant level through 6 June, then declined progressively and ceased altogether on 10 June (Fig. 3). Multiplets 5 and 6 contained approximately 4000 and 500 events, respectively, accounting for most of the observed repeating seismicity. At times the repeating events accounted for $>80 \%$ of the total detected seismicity, with a mean of $38 \%$ of all detected events over the course of the entire sequence (Fig. 3b). The rate of occurrence of nonrepeating seismicity remained constant between episodes.

We attempted to determine the magnitude of the multiplet events, something that is routinely done by the PNSN using coda duration (Dewberry and Crosson, 1995). Coda durations are typically extended when recorded on stations on the edifice of Mount Rainier due to the scattering nature of the 
volcano. Thus for reliable coda measurements for earthquake magnitude, only stations off the edifice of Mount Rainier are considered in routine analysis. Due to the small size of the multiplet events and the strong attenuation limiting wave propagation off the volcano, we could not obtain a reliable estimate of magnitude using the coda duration. Instead we compared band-limited $(1-6 \mathrm{~Hz})$ amplitudes of 62 located earthquakes within the edifice of Mount Rainier from the PNSN catalog to band-limited amplitudes of the 2010 multiplets, and found that the amplitudes of the largest multiplet events were consistent with amplitudes recorded for PNSN catalog events with coda magnitudes between -1 and 0 . An independent estimate of magnitude using displacement spectra (e.g. Aki and Richards, 2002) gave a slightly higher estimate of magnitude $(0-0.5$ for the largest events); however, it was difficult to identify distinct bodywave phases for this calculation.

Events within individual multiplets systematically varied in amplitude, recurrence interval, and cross-correlation coefficient with time (Fig. 5). To combine amplitude and duration into one parameter we determined the pseudoenergy for each event, with pseudo-energy being the integral of the event envelope (Rowe and others, 2002). In the first pulse, multiplets 5 and 6 initially built to a high event rate (low recurrence interval) within a few hours of the onset of each multiplet (Fig. 3). The recurrence intervals then increased until 28 May, after which they remained constant until the end of the first phase (Fig. $5 \mathrm{a}$ and b). The pseudoenergy of multiplet 5 slowly increased over the next several days, peaking around 23 May (Fig. 5c). From this point, the pseudo-energy of multiplet 5 progressively declined to a minimum just prior to the cessation of the first pulse on 1 June. Multiplet 6 had relatively small pseudo-energies during the entire first phase, but there were proportionately more large events prior to 25 May than after (Fig. 5d). Pseudo-energy levels increased again with the onset of the second pulse (Fig. 5c). Recurrence intervals for multiplet 5 dropped dramatically at the start of the second pulse and remained low through 5 June before progressively increasing through to the end of the second pulse. Larger recurrence intervals in multiplet 5 generally corresponded with higher pseudo-energies, especially during the second phase (Fig. 5a and c). Cross-correlation values between the first event and every other event gradually declined for both multiplets, except between 30 and 31 May when cross-correlation values declined fairly abruptly for multiplet 5 (Fig. 5e and f).

One of the more intriguing results of our cross-correlation analyses is the observation that the two dominant multiplets behaved very differently. Multiplet 5 occurred during both seismicity pulses, had significant variability in pseudoenergy levels and had shorter recurrence that showed no diurnal variation (Fig. 5a and c). In contrast, multiplet 6 occurred only during the first seismicity pulse and had a relatively small range of pseudo-energy levels compared to multiplet 5 (Fig. 5d). Perhaps most intriguingly, multiplet 6 had event rates that were periodic in time, particularly between 21 and 25 May when recurrence intervals were systematically lower (event rates higher) during the night (Fig. 5b), with event rate peaks lagging the peak daily temperatures by $\sim 6 \pm 2$ hours.

Amplitudes for individual events in both multiplets were too small for picking sufficient phase-arrival times to generate well-constrained event locations. In order to improve the signal-to-noise ratio, we stacked 4006 events

\section{Multiplet 5}

a

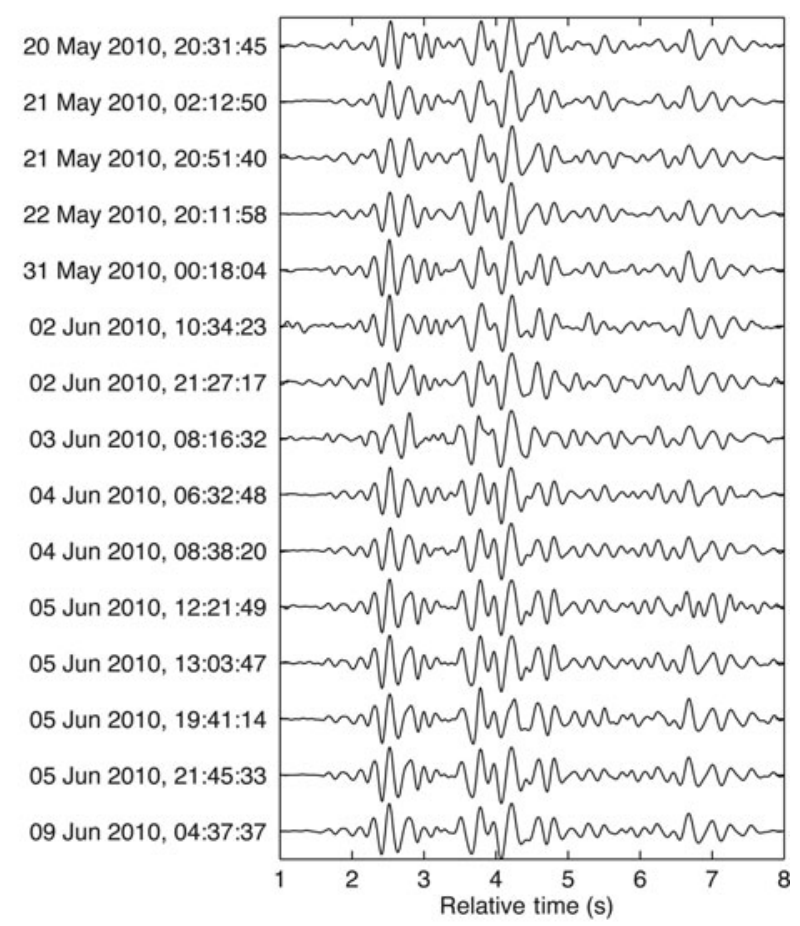

b

Multiplet 6

Fig. 4. Fifteen representative waveforms from (a) multiplet 5, and (b) multiplet 6, as recorded on station STAR (Fig. 1). Waveforms are filtered between 0.5 and $8 \mathrm{~Hz}$.

from multiplet 5 (Fig. 6) and measured P-wave arrival times from the stack on six stations (RCS, RCM, STAR, RER, FMW and LO2). No reliable $S$-wave arrival times were possible on the event stacks. Using these arrival times and the standard PNSN hypocenter determination routines and Mount Rainier one-dimensional velocity model resulted in a near-surface $(0.04 \mathrm{~km})$ location $0.9 \mathrm{~km}$ northwest of the summit on the upper part of Winthrop Glacier (Fig. 1, star). The elevation of 
a

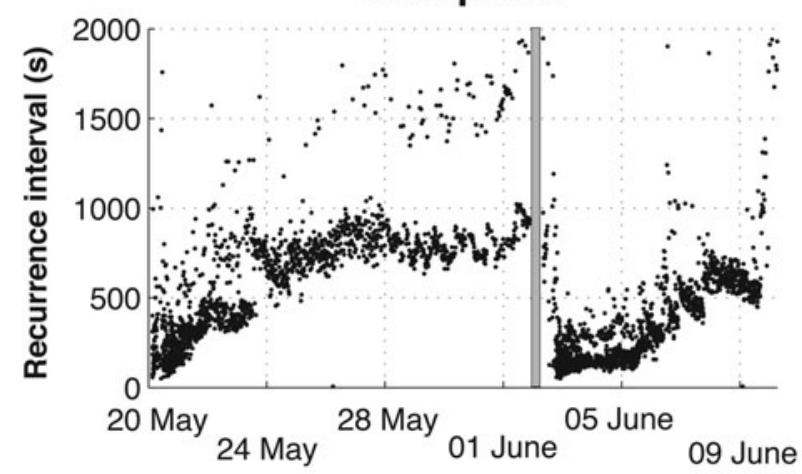

C

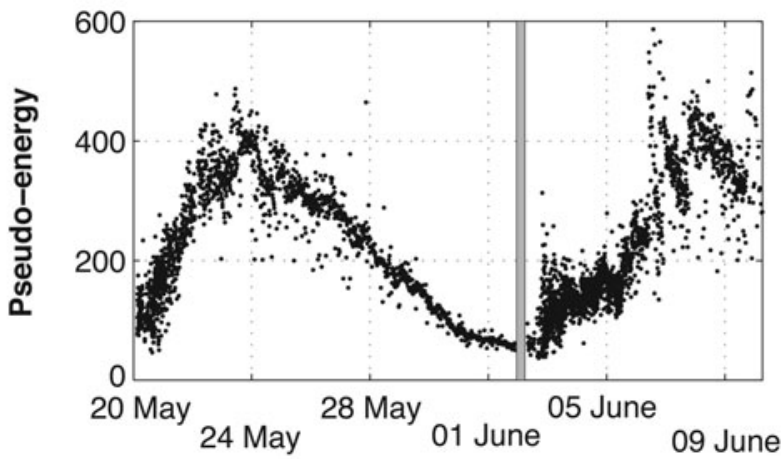

e

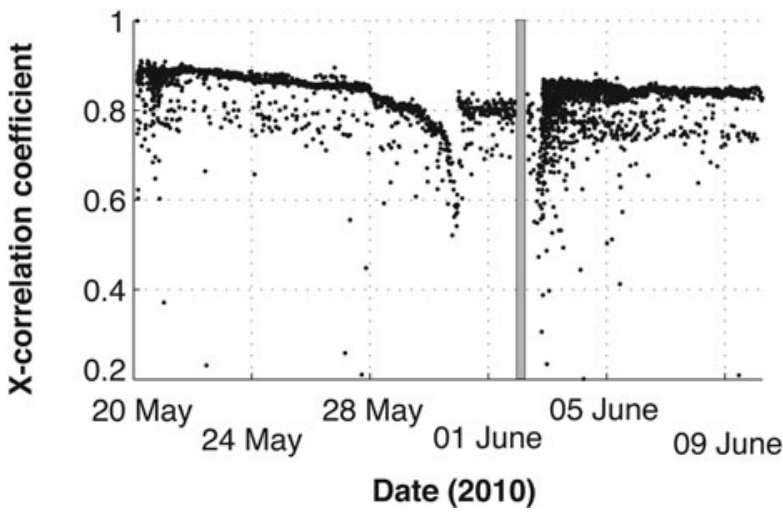

Multiplet 6

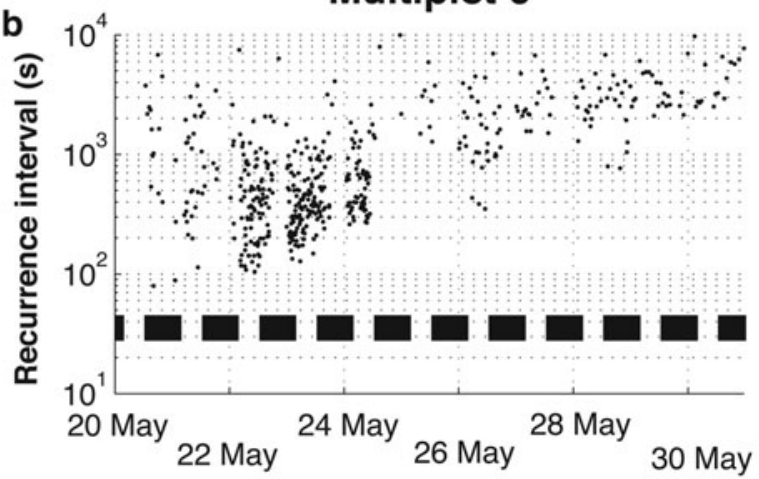

d

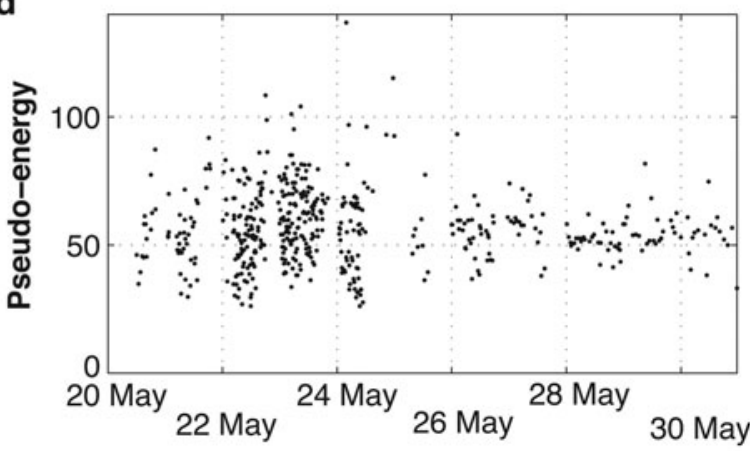

f

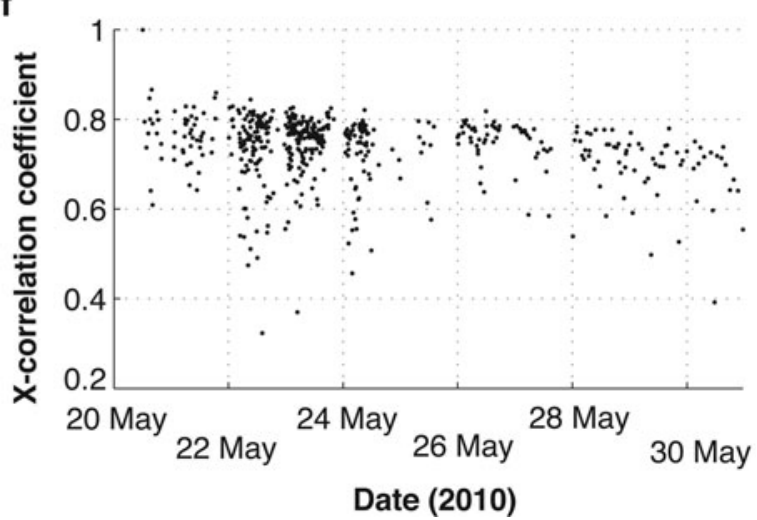

Fig. 5. (a, c, e) Recurrence interval (a), pseudo-energy (c) and cross-correlation coefficient (e) of individual events within multiplet 5 recorded on station STAR (Fig. 1). (b, $d, f)$ Recurrence interval (b), pseudo-energy (d) and cross-correlation coefficient (f) of individual events within multiplet 6 recorded on STAR. The dark bars in (d) show periods of daylight. The cross-correlation coefficient is calculated with respect to the first detected event within the multiplet. The faint doubling at twice the main recurrence interval reflects missed events in the automatic detection scheme. The gray rectangles in (a), (c) and (e) are times when the multiplets paused between phases.

the surface is $\sim 4100$ ma.s.l. at this point. The formal location errors were $0.1 \mathrm{~km}$ horizontally and $2.2 \mathrm{~km}$ vertically with a root mean square of $0.16 \mathrm{~s}$; however, given the small number of phase picks, the true error particularly in the horizontal direction is likely higher. The vertical location errors are high, but the waveforms are typical of near- or at-surface events with elongated codas, unclear phase arrivals and high attenuation. We also located the stacked 'event' in the three-dimensional velocity model of Moran and others (2000) and achieved a similar result. No formal location could be determined for multiplet 6 as the stacked waveforms from 508 events were still too emergent to accurately pick enough phase arrivals. The phase picks that we could obtain from those stations on the edifice of the volcano (RCS, RCM, STAR) had relative phase arrival times that were consistent with a location near multiplet 5 . At least two other minor multiplets occurring during the two seismicity pulses had phase arrivals with moveouts that were clearly different from the moveout of multiplet 5 arrivals, suggesting that shallow sources on other parts of the mountain may also have been seismically active.

The spread in locations within multiplet 5 can be independently estimated by utilizing the highly correlated waveforms. Geller and Mueller (1980) suggest that highly correlated waveforms must be within a quarter-wavelength so as not to be influenced by the structure between the two source locations. Given a dominant S-wave frequency of $3 \mathrm{~Hz}$ and assuming an S-wave velocity of $1.49 \mathrm{~km} \mathrm{~s}^{-1}$ (using the P-wave velocity of $2.66 \mathrm{~km} \mathrm{~s}^{-1}$ determined by Thelen and others (2008) for the uppermost $500 \mathrm{~m}$ at Mount St Helens), the spread in locations in theory should be no more than $\sim 125 \mathrm{~m}$. We can further reduce the location-spread estimate by using the time offsets from our cross-correlation analyses. The greatest time offset on any station during the 

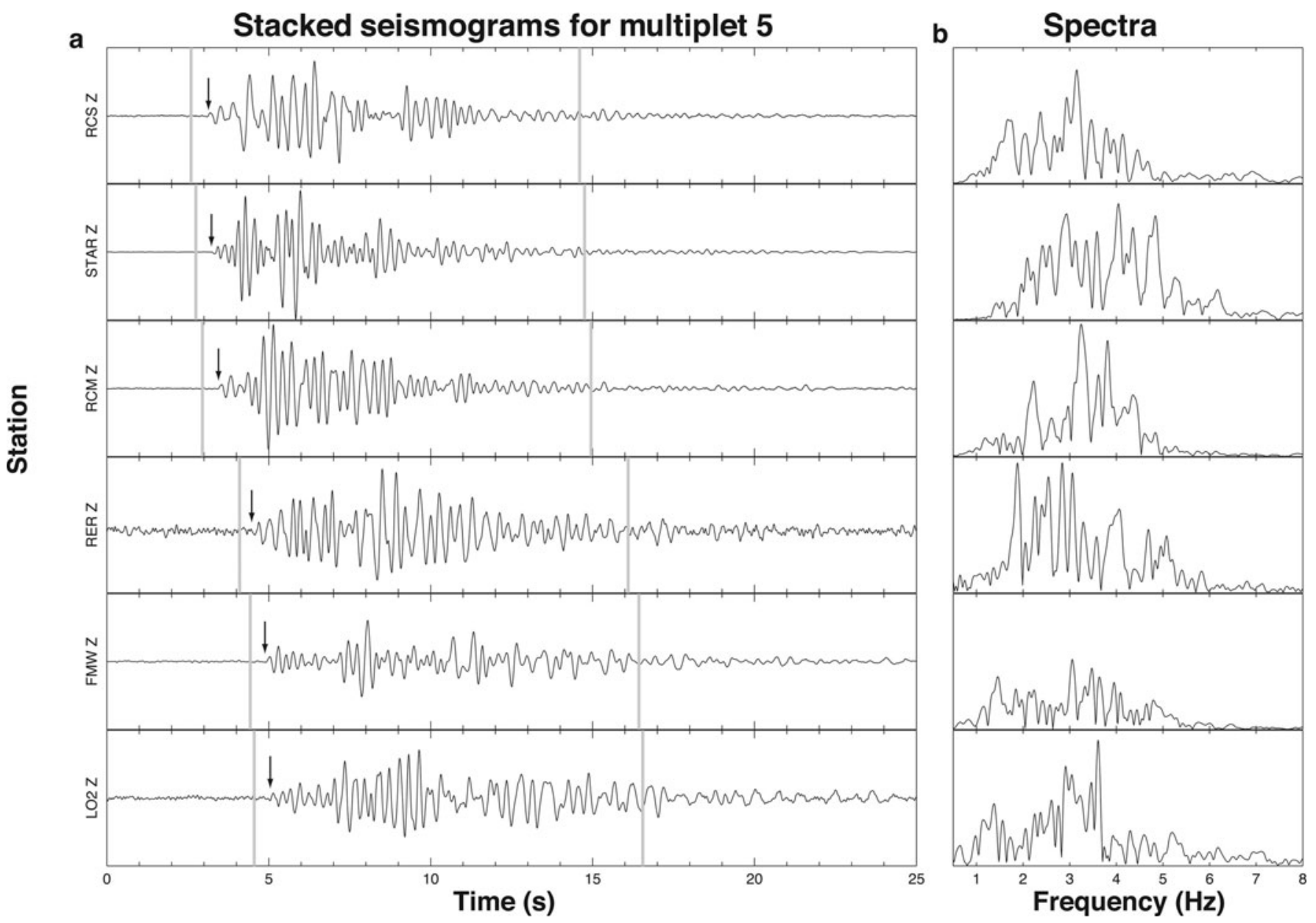

Fig. 6. Stacked normalized waveforms (a) and spectra (b) of multiplet 5 on several stations (see Fig. 1 for station locations). Gray vertical lines indicate time windows taken for the spectra. Seismograms for distant stations RER, FMW and LO2 were bandpass-filtered at 0.5-10 Hz to improve clarity. Arrows show first arrival times for each station.

sequence was $\sim 0.05 \mathrm{~s}$, giving an estimate of $\sim 75 \mathrm{~m}$ for the maximum distance between one event and all others in the multiplet sequence.

\section{MULTIPLET SOURCE MECHANISM}

Based simply on the location of the dominant multiplet under Winthrop Glacier and the shallow depth of the earthquakes, we may restrict the source of the multiplets to either a glacial source (small effect on volcanic hazard) or a shallow hydrothermal source (large effect on volcanic hazard). There is no unique parameter to discriminate the two source types, and we weigh the evidence for both below.

\subsection{Seismic constraints}

The occurrence of multiplets requires that the seismogenic source be repeatable and non-destructive. Our analyses of multiplet 5 indicate that the source is located at very shallow depths under Winthrop Glacier, and that the spread in locations indicates a source area of $\sim 75-100 \mathrm{~m}$ radius. All of these characteristics are consistent with both a glacial and hydrothermal origin. One key issue is to determine whether the waveforms themselves reflect source or path effects. By examining the frequency content of seismograms from different stations, it is possible to assess whether waveform spectra reflect the source or are predominantly influenced by propagation effects such as heterogeneous scattering due to high/variable attenuation (e.g. Lahr and others, 1994). If spectral peaks are shared at many or all stations, then they likely represent frequencies that are characteristic of the source process; if they are different, then the spectra likely reflect path effects (e.g. Waite and others, 2008). We found no common spectral peaks in spectra for stacked seismograms from multiplet 5 (Fig. 6), indicating that the seismograms dominantly reflect path effects. We also found that there were in general higher-frequency peaks on stations closer to the source (RCS, STAR, RCM), and lower-frequency peaks on stations further from the source (FMW, LO2), indicating attenuation during propagation. Such path effects are consistent with the findings of Weaver and Malone (1979) in their studies of glacial earthquakes, though the attenuation could also be explained by the passage of waves through pervasively altered rock that may exist around a hydrothermal area.

Resistivity and magnetic modeling of Mount Rainier by Finn and others (2001) detected altered rock near the epicentral region. The epicenter and altered rock lie in the source area for the $5.6 \mathrm{ka}$ BP Osceola Mudflow (Finn and others, 2001), and it is unclear if the altered rock is the product of an extinct hydrothermal system or a currently active hydrothermal system. Fumaroles do exist in several areas at the summit of Mount Rainier (Frank, 1995). Interestingly, besides the two dominant multiplets, there were several multiplets with smaller populations that were clearly sourced from many different areas of the volcano. A model invoking a hydrothermal source for the multiplets 


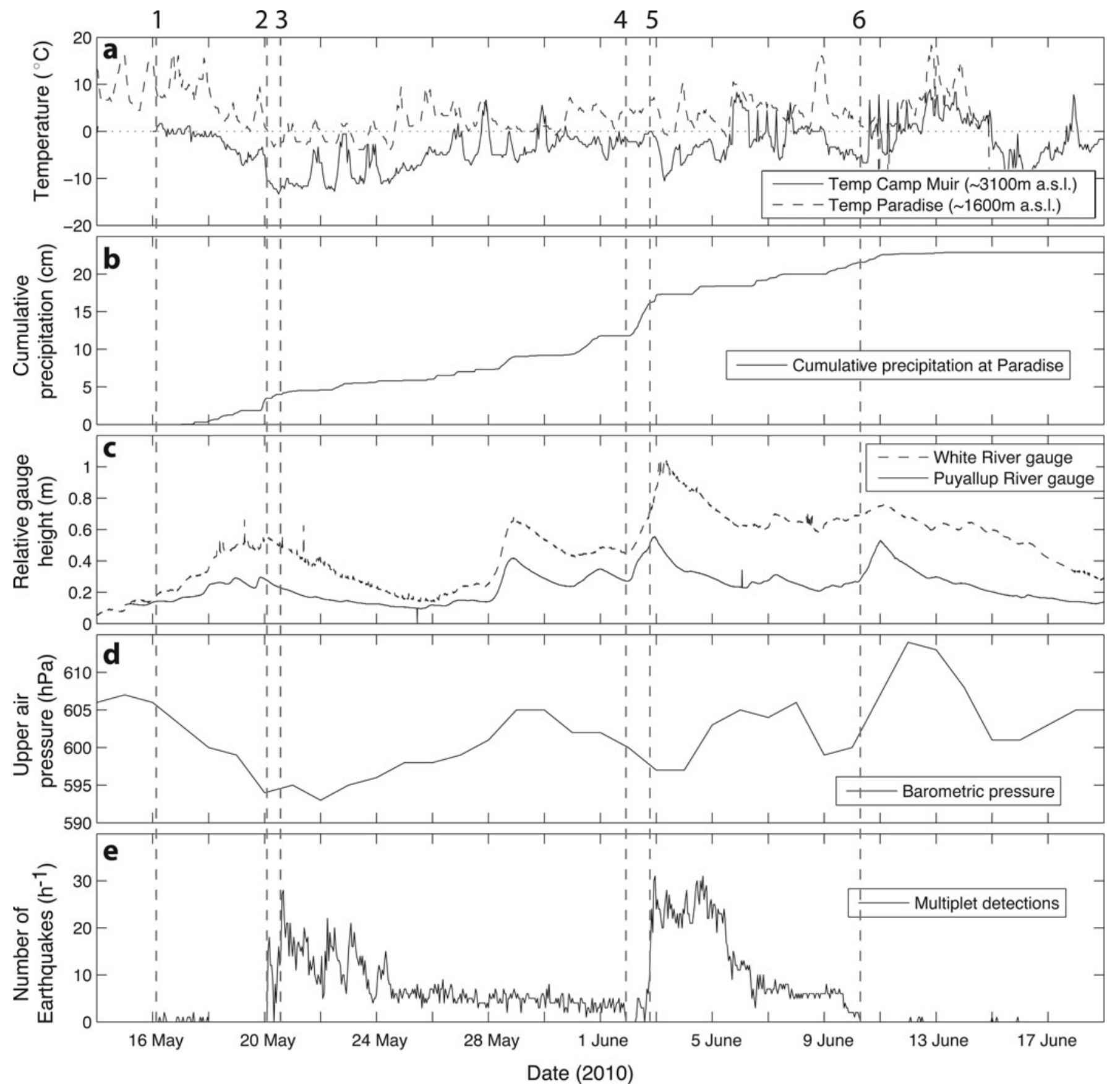

Fig. 7. Plot showing connection of multiplet activity with weather. (a) Temperatures recorded at Paradise and Camp Muir; (b) cumulative precipitation recorded at Paradise; (c) stream gauge heights for the White River downstream of Winthrop and Emmons Glaciers and the Puyallup River downstream of glaciers on western slopes; (d) upper-air barometric pressure interpolated to $4200 \mathrm{~m}$ from the nearest NCEP/ NCAR reanalysis gridpoint (http://ingrid.Idgo.columbia.edu/ SOURCES/.NOAA/.NCEP-NCAR/.CDAS-1/); and (e) number of multiplet events detected per hour. Vertical dashed line 1 indicates the onset of the repeating sequences, 2 shows the onset of the 20 May storm, 3 indicates the gap where multiplet activity ceases, and 4 indicates the onset of the second multiplet episode of activity coinciding with the onset of the 2 June storm and rising stream-gauge levels.

must explain the simultaneous pressurization of the hydrothermal system on several parts of the volcano. Such a pressurization without a deeper response from the volcanic and/or hydrothermal system seems unlikely.

\subsection{Meteorologic constraints}

To further explore the source of the multiplets, we examined records from nearby meteorological stations in order to investigate whether the multiplets occurred in association with temperature, precipitation, snow loading or water-flux changes that could, in turn, have influenced glacier motion.
Figure 7 shows temperatures recorded at weather stations at Camp Muir ( 3100 ma.s.I.) and Paradise (1600 m a.s.l.) (see Fig. 1 for locations), along with cumulative precipitation, including both rain and snow (melted), recorded at Paradise and stream-gauge data from two instruments. One gauge (USGS Water Resources gauge 12092000) is $\sim 20 \mathrm{~km}$ downstream of Mount Rainier on the Puyallup River, which is fed by several glaciers on the western flank. The second (USGS Water Resources gauge 12098500) is $\sim 60 \mathrm{~km}$ downstream of Rainier on the White River, which is fed by streams emanating from Winthrop and Emmons Glaciers 
(Fig. 1). The gauge is also $\sim 3 \mathrm{~km}$ downstream of a flood control dam, but overall flow patterns are similar to those observed at neighboring stream gauges, with some rapid spikes in flow that are likely due to flood-control measures. Both gauges also receive input from lower-elevation portions of their watersheds and thus do not solely indicate processes on the mountain. Barometric pressure is not measured on Mount Rainier, so assuming upper-air data vary slowly spatially, we have included data interpolated up to the approximate elevation of the multiplet 5 location from the nearest US National Centers for Environmental Prediction and National Center for Atmospheric Research (NCEPNCAR) reanalysis gridpoint (Fig. $7 d$ ).

A few scattered multiplets appeared on 16 May, but the swarm began sharply on 20 May, shortly after a storm system passed through the area (Fig. 7, label 2). The storm is signified by a drop in both barometric pressure and temperature. It brought a short period of intense precipitation ( $\sim 2 \mathrm{~cm}$ in 4 hours), which would have fallen as snow at the elevation where multiplet 5 is located $(\sim 4100 \mathrm{~m}$ a.s.I). Both multiplets 5 and 6 were present during this first pulse. Multiplet rates gradually decayed over the next several weeks and eventually died out on 1 June. On 2 June a second storm resulted in $\sim 5.5 \mathrm{~cm}$ of precipitation (melted) over 21 hours, the largest daily rainfall total of any time interval during our study period (Fig. 7b, label 5). This reinvigorated multiplet activity to even higher rates than before. Multiplet 5 reappeared, but multiplet 6 did not. Multiplet rates again gradually decayed and then ceased on 10 June.

This close correlation between the two pulses of seismicity and the two passing storms suggests that the source is sensitive to weather forcing. The correlation of multiplet appearance with weather suggests three possible triggering mechanisms: increased meteoric or meltwater flow rates, snow loading or a drop in barometric pressure. The sudden addition of meteoric and/or meltwater to the glacial system could change glacier behavior and result in seismicity (e.g. Weaver and Malone, 1979; Fountain and Walder, 1998). However, at the elevation of multiplet 5 $(\sim 4100 \mathrm{~m})$ and likely the other multiplets, temperatures will be below freezing and that precipation is in the form of snow, making snow loading a more likely trigger.

Hydrothermal activity could also be influenced by the addition of water through near-surface networks of cracks. However, precipitation, as snow, will likely not enter the hydrothermal system. Hydrothermal activity could be influenced by a drop in barometric pressure, which decreases the boiling point of water, increasing water flux from below. Mount Rainier has an active hydrothermal system with meteoric and magmatic components (e.g. Frank, 1995), so hydrothermal processes are a legitimate source hypothesis. However, the barometric pressure drops were not extraordinary and multiplet activity did not respond to similar drops in barometric pressure later in June (Fig. 7e) that were not accompanied by intense precipitation. Tectonic or volcanic sources would not be as likely to respond to weather forcing, leaving a glacial source as the most likely candidate.

\subsection{Stick-slip as preferred source model}

We believe that volcanic-process-related source models can be discounted for the Mount Rainier multiplet sequence based on the location and shallow depth of the multiplet 5 stacked 'event', inconsistent frequency peaks between stations for the multiplet 5 stacks (Fig. 6), the apparent meteorological influence on the start of the two seismicity pulses (Fig. 7) and the diurnal variability in event rate of multiplet 6 (Fig. 5). For a glacier source, we can discard source mechanisms involving resonance of glacial conduits (e.g. St Lawrence and Qamar, 1979), cracks (e.g. Métaxian and others, 2003) or the entire glacial structure (e.g. Wolf and Davies, 1986) because there are no consistent spectral peaks between stations or evidence of harmonics. Other authors have interpreted low-frequency signals in glacial environments as being related to calving processes (Qamar, 1988; Nettles and others, 2008), to collapses of large chunks of glacial ice (Roux and others, 2008; Jónsdóttir and others, 2009) or to crevassing (Neave and Savage, 1970). Event rates at Mount Rainier during 20 May-10 June were quite high, up to 30 events $h^{-1}$, with a median of 6 events $h^{-1}$. It is difficult to imagine a nearly continuous, regular and highly repetitive icefall or crevassing source being active for such an extended period of time, particularly given that there were no reports from climbers or National Park Service employees of unusual glacial activity or large-scale disturbances of glacier surfaces at the time of the multiplet episodes. Thus we believe that such source mechanisms are also unlikely candidates for explaining the Mount Rainier multiplets.

We believe that of all the candidate source models, stickslip sliding along the contact between the ice and substrate is the most logical source model. Weaver and Malone (1976, 1979), Ekström and others (2003), Wiens and others (2008) and Winberry and others (2009) all present evidence of lowfrequency events being caused by sliding along the bedrock/ glacier interface. Weaver and Malone (1976) demonstrated that low-frequency signatures with protracted durations may be generated by propagation through the ice/rock interface. In particular, they found that glacial earthquakes recorded on an ice station showed large amplitudes, impulsive onsets, broadband character and short codas, whereas the same events recorded at a station installed $\sim 100 \mathrm{~m}$ away on rock exhibited more emergent arrivals, longer codas and a substantially lower-frequency character, similar to the character of the 2010 Mount Rainier multiplets. The events recorded as part of the Weaver and Malone (1976) study were interpreted as being caused by discrete glacial movements. A similar experiment with an ice site and rock site at the glacially capped Cotopaxi volcano, Ecuador, showed the same pattern (Métaxian and others, 2003).

Several studies provide additional support for the stickslip source model. Malone and Haulter (2003) generated synthetic seismograms for a stick-slip source in a velocity model similar to that found on ice-clad volcanoes. They found that the dominant low-frequency character of the waveforms could be reproduced by placing a stick-slip source at the interface between a shallow high-velocity layer (glacier ice, $\mathrm{Vp}=3.2 \mathrm{~km} \mathrm{~s}^{-1}$ ) and a stack of alternating lowand very low-velocity layers (loosely consolidated volcanic material, $\mathrm{Vp}=0.8 \mathrm{~km} \mathrm{~s}^{-1}$ ). In contrast, a source several $\mathrm{km}$ below the shallow layers produced synthetic seismograms more similar to those of volcano-tectonic events. Additionally, Caplan-Auerbach and Huggel (2007) demonstrated that low-frequency repeating signals at Iliamna volcano, Alaska, with similarities to the Mount Rainier multiplets were generated by accelerating stick-slip ramp failure at or near the base of glaciers. 


\section{DISCUSSION}

We suggest that the highly repetitive nature of the signals is due to ice sliding over relatively stationary asperities. Presuming this to be the correct model, locations from picks of stacked multiplet 5 seismograms indicate that the asperity was near the head of Winthrop Glacier. This is not an unlikely scenario, as the upper portion of Winthrop Glacier has crevassed ice domes formed by the breaking of ice over the irregular subsurface (Driedger and Moore, 1986). The other multiplets could not be located, but the fact that many other multiplets had relative arrival-time patterns and relative between-station amplitudes that were similar to those for multiplet 5 suggests that they were also occurring beneath or near Winthrop Glacier. The gradual decorrelation of both multiplets 5 and 6 (Figs $5 e$ and f) could be a result of slow morphological changes to the glacier and subsurface, or to slow migration of the source down-glacier.

The fact that the multiplets comprising the 2010 multiplet sequence were not observed outside the 3 week swarm indicates a short-term forcing mechanism. If the multiplets were connected to basal sliding velocities, their occurrence during this time may be explained by an increase in basal sliding velocities to a rate where stick-slip sliding dominates and is seismically observed, whereas at lower velocities sliding may be aseismic. Initially we thought the appearance of the multiplet swarms may be related to a glacial phenomenon commonly referred to as the 'spring speedup', a temporary acceleration in basal sliding often observed as a several-fold increase in surface velocities triggered by a rapid introduction of spring meltwater to the glacial system (e.g. Fountain and Walder, 1998; Harper and others, 2007; Fudge and others, 2009). However, temperatures at Camp Muir did not often exceed the freezing point during the multiplet swarm (Fig. 7a). Our location for multiplet 5 is $\sim 1 \mathrm{~km}$ higher than Camp Muir, and, at that elevation, surface temperatures were probably several degrees below freezing. In other words, there likely would be little meltwater or liquid precipitation at the presumed elevation of the multiplet sequences. Even if the glaciers sped up at lower elevations due to increased water input, it would take more than the few hours it took multiplet activity to respond to intense precipitation. For example, Hodge (1974) measured a velocity increase pulse traveling down-glacier at $20 \mathrm{~km} \mathrm{a}^{-1}$ on Nisqually Glacier on the south side of the mountain, much too slow for such a rapid response to weather forcing. The diurnal occurrence of multiplet 6 , but not multiplet 5 , shows that there are second-order effects on the occurrence of some events; however, the first-order effect is clearly related to the passage of storms over the volcano. Speculating on these second-order effects is beyond the scope of this paper.

The question remains: why haven't we noticed sequences like the 2010 multiplets in other years if they are simply triggered by storms and rapid snow loading, which occurs often at Mount Rainier? Snow levels were not anomalously high in 2010 (station PCV, Northwest Avalanche Center). One possibility is that they do occur, but on a smaller scale during most years such that the multiplet seismicity is too small to be noticed. There currently is no automated search for multiplet events on Mount Rainier. The sequences in the 1990s and 2010 were detected by visual inspection of continuous seismograms when their repetitive nature caught someone's attention. Given the relatively high level of background glacier seismicity at Mount Rainier, it is certainly possible that other swarms of repeating events with smaller amplitudes or less regular repeat times have gone unnoticed. Weaver and Malone (1979) found high variability between years (up to fourfold differences) in rates of low-frequency earthquakes on Mount Rainier, that sometimes related to observable changes in glacier behavior. The base of a glacier is also a dynamic environment and it may be that in some years the conditions along the basal plane are more favorable for producing extended multiplet sequences than in others.

If our hypothesis of small asperities along the base of the glacier is correct, then the seismic source dimensions involved in rupturing those asperities should be small with respect to the size of the glacier. The approximate magnitude of each of these events is $M d-1$ to 0 . Assuming that the magnitudes are equivalent to moment magnitudes $(\mathrm{Mw})$, we can obtain the moment (Mo) for each event using $\mathrm{Mw}=\log (\mathrm{Mo}) / 1.5-6.07$ to obtain a moment range of $4.03 \times 10^{7}$ to $1.27 \times 10^{9} \mathrm{Nm}$. Using the definition of moment, $M o=\mu S A$, where $S$ is average slip per event, $A$ is the slip area involved and $\mu$ is the shear modulus (with $\mu$ lying in the range $10^{9}-10^{10} \mathrm{~Pa}$ including values for low- and high-density rocks as well as ice), we can calculate a range of slips and corresponding slip areas. To constrain the total motion of the glacier over the duration of the two multiplet pulses, we use the range of velocities measured on nearby Nisqually Glacier (Fig. 1) and find that the glaciers could have moved as little as $0.5 \mathrm{~m}$ or as much as $50 \mathrm{~m}$ over a 3 week period (Hodge, 1974). If we assume that (1) each event represents discrete slip at the base of a glacier, and (2) Nisqually Glacier is a good analog to Winthrop Glacier, then we can divide this motion by the 4000 events making up multiplet 5 and determine a lower estimate of $0.1 \mathrm{~mm}$ for slip per event. With these constraints, we can restrict the source size to large slips on a small area (lowest possible being $10 \mathrm{~cm}$ of slip on an area of $0.4-100 \mathrm{~m}^{2}$ ) or small slips on a relatively large area (limit $0.1 \mathrm{~mm}$ on an area of 30$10000 \mathrm{~m}^{2}$ ). Even the largest estimated slip area is just $0.01 \mathrm{~km}^{2}$, much smaller than the total area of the upper portion of Winthrop Glacier, so these estimates indicate that stick-slip motion along only a localized portion of the glacier is required to explain the multiplets.

\section{CONCLUSIONS}

During a 3 week period in May-June 2010, >4500 repeating low-frequency seismic events (or 'multiplets') occurred near the summit of Mount Rainier, with most events within each multiplet set occurring at regular intervals. The event rates during the sequence were correlated with the passing of two storm systems that brought heavy precipitation, which fell as snow at the elevation of the location of the largest multiplet set. This leads us to believe that the multiplet swarms are related to glaciers reacting to rapid snow loading, though we cannot definitely rule out a very shallow hydrothermal source. Our preferred source mechanism to explain the repeating behavior of the multiplets is repeated basal slip of Winthrop Glacier, and possibly other glaciers, over asperities at their beds. Our interpretation further illustrates the difficulty of interpreting seismic signals, in particular low-frequency events, on glacier-clad volcanoes, and the importance of having sufficient instrumentation to discriminate between volcanic and glacial sources. Having a seismometer on the glacier above the asperity would aid 
in our interpretation; however, keeping a permanent seismometer operational on a high-altitude temperate glacier is difficult and the source area is too often inaccessible for a temporary deployment.

\section{ACKNOWLEDGEMENTS}

We acknowledge Matt Haney, Joseph Walder and four anonymous reviewers for comments on the original manuscript.

\section{REFERENCES}

Aki K and Richards PG (2002) Quantative seismology, 2nd edn. University Science Books, Sausalito, CA

Allen RV (1978) Automatic earthquake recognition and timing from single traces. Bull. Seismol. Soc. Am., 68(5), 1521-1532

Caplan-Auerbach J and Huggel C (2007) Precursory seismicity associated with frequent, large ice avalanches on Iliamna volcano, Alaska, USA. J. Glaciol., 53(180), 128-140 (doi: 10.3189/172756507781833866)

Caplan-Auerbach J, Thelen WA and Moran SC (2009) An unusual cluster of low-frequency earthquakes at Mount Baker, Washington, as detected by a local broadband network. [Abstract V23D2111] Am. Geophys. Union, Fall Meet. http://adsabs.harvard. edu/abs/2009AGUFM.V23D2111C

Chouet BA (1996) Long-period volcano seismicity: its source and use in eruption forecasting. Nature, 380(6572), 309-316 (doi: 10.1038/380309a0)

Danesi S, Bannister S and Morelli A (2007) Repeating earthquakes from rupture of an asperity under an Antarctic outlet glacier. Earth Planet. Sci. Lett., 253(1-2), 151-158 (doi: 10.1016/j.epsl. 2006.10.023)

Dewberry SR and Crosson RS (1995) Source scaling and moment estimation for the Pacific Northwest seismograph network using S-coda amplitudes. Bull. Seismol. Soc. Am., 85(5), 1309

Driedger CL and Kennard PM (1986) Ice volumes on Cascade volcanoes: Mount Rainier, Mount Hood, Three Sisters, and Mount Shasta. (USGS Prof. Pap. 1365) US Geological Survey, Reston, VA

Driedger CL and Moore ST (1986) A visitor's guide to Mount Rainier glaciers. Pacific Northwest National Parks and Forests Association, Seattle, WA

Ekström G, Nettles M and Abers GA (2003) Glacial earthquakes. Science, 302(5645), 622-624 (doi: 10.1126/science.1088057)

Ewert JW, Guffanti M and Murray TL (2005) An assessment of volcanic threat and monitoring capabilities in the United States: framework for a national volcano early warning system. USGS Open File Rep. 2005-1164.

Finn CA, Sisson TW and Deszcz-Pan M (2001) Aerogeophysical measurements of collapse-prone hydrothermally altered zones at Mount Rainier volcano. Nature, 409(6820), 600-603 (doi: 10.1038/35054533)

Fountain AG and Walder JS (1998) Water flow through temperate glaciers. Rev. Geophys., 36(3), 299-328 (doi: 10.1029/ 97RG03579)

Frank D (1995) Surficial extent and conceptual model of hydrothermal system at Mount Rainier, Washington. J. Volcanol. Geotherm. Res., 65(1-2), 51-80 (doi: 10.1016/0377-0273(94) 00081-Q)

Frémont M-J and Malone SD (1987) High precision relative locations of earthquakes at Mount St. Helens, Washington. J. Geophys. Res., 92(B10), 10223-10236 (doi: 10.1029/ JB092iB10p10223)

Fudge TJ, Harper JT, Humphrey NF and Pfeffer WT (2009) Rapid glacier sliding, reverse ice motion and subglacial water pressure during an autumn rainstorm. Ann. Glaciol., 50(52), 101-108 (doi: 10.3189/172756409789624247)
Geller RJ and Mueller CS (1980) Four similar earthquakes in central California. Geophys. Res. Lett., 7(10), 821-824 (doi: 10.1029/ GL007i010p00821)

Harper JT, Humphrey NF, Pfeffer WT and Lazar B (2007) Two modes of accelerated glacier sliding related to water. Geophys. Res. Lett., 34(12), L12503 (doi: 10.1029/2007GL030233)

Hoblitt RP, Walder JS, Driedger CL, Scott KM, Pringle PT and Vallance JW (1995) Volcano hazards from Mount Rainier, Washington. USGS Open File Rep. 95-273

Hodge SM (1974) Variations in the sliding of a temperate glacier. J. Glaciol., 13(69), 349-369

Jónsdóttir K and 6 others (2009) Glacial long period seismic events at Katla volcano, Iceland. Geophys. Res. Lett., 36(11), L11402 (doi: 10.1029/2009GL038234)

Lahr JC, Chouet BA, Stephens CD, Power JA and Page RA (1994) Earthquake classification, location, and error analysis in a volcanic environment: implications for the magmatic system of the 1989-1990 eruptions at redoubt volcano, Alaska. J. Volcanol. Geotherm. Res., 62(1-4), 137-151 (doi: 10.1016/ 0377-0273(94)90031-0)

Lesage Ph and Surono (1995) Seismic precursors of the February 10, 1990 eruption of Kelut volcano, Java. J. Volcanol. Geotherm. Res., 65(1-2), 135-146 (doi: 10.1016/0377-0273(94)00051-H)

Luckett R, Loughlin S, De Angelis S and Ryan G (2008) Volcanic seismicity at Montserrat, a comparison between the 2005 dome growth episode and earlier dome growth. J. Volcanol. Geotherm. Res., 177(4), 894-902 (doi: 10.1016/j.jvolgeores. 2008.07.006)

Malone S and Haulter A (2003) How glacier-quakes can mimic low-frequency volcanic earthquake seismograms. [Abstract 12833] EGS-AGU-EUG Joint Assembly http://adsabs.harvard. edu/abs/2003eaeja....12833m

Métaxian J-P, Araujo S, Mora M and Lesage P (2003) Seismicity related to the glacier of Cotopaxi Volcano, Ecuador. Geophys. Res. Lett., 30(9), 1483 (doi: 10.1029/2002GL016773)

Moran SC, Zimbelman DR and Moran SD (2000) A model for the magmatic-hydrothermal system at Mount Rainier, Washington, from seismic and geochemical observations. Bull. Volcanol., 61(7), 425-436 (doi: 10.1007/PL00008909)

Moran SC, Thelen WA, Caplan-Auerbach J, Malone SD and Wright A (2009) An anomalous swarm of low-frequency events at Mount Baker, Washington, June-August 2009. [Abstract V23D2112] Am. Geophys. Union Fall Meet. http://adsabs.harvard. edu/abs/2009AGUFM.V23D2112M

Neave KG and Savage JC (1970) Icequakes on the Athabasca Glacier. J. Geophys. Res., 75(8), 1351-1362 (doi: 10.1029/ JB075i008p01351)

Nettles M and 12 others (2008) Step-wise changes in glacier flow speed coincide with calving and glacial earthquakes at Helheim Glacier, Greenland. Geophys. Res. Lett., 35(24), L24503 (doi: 10.1029/2008GL036127)

Petersen T (2007) Swarms of repeating long-period earthquakes at Shishaldin Volcano, Alaska, 2001-2004. J. Volcanol. Geotherm. Res., 166(3-4), 177-192 (doi: 10.1016/j.jvolgeores.2007. 07.014)

Qamar A (1988) Calving icebergs: a source of low-frequency seismic signals from Columbia Glacier, Alaska. J. Geophys. Res., 93(B6), 6615-6623 (doi: 10.1029/JB093iB06p06615)

Ratdomopurbo A and Poupinet G (1995) Monitoring a temporal change of seismic velocity in a volcano: application to the 1992 eruption of Mt. Merapi (Indonesia). Geophys. Res. Lett., 22(7), 775-778 (doi: 10.1029/95GL00302)

Roux P-F, Marsan D, Metaxian J-P, O'Brien G and Moreau L (2008) Microseismic activity within a serac zone in an alpine glacier (Glacier d'Argentière, Mont Blanc, France). J. Glaciol., 54(184), 157-168 (doi: 10.3189/002214308784409053)

Rowe CA, Aster RC, Borchers B and Young CJ (2002) An automatic, adaptive algorithm for refining phase picks in large seismic data sets. Bull. Seismol. Soc. Am., 92(5), 1660-1674 (doi: 10.1785/ 0120010224) 
St Lawrence W and Qamar A (1979) Hydraulic transients: a seismic source in volcanoes and glaciers. Science, 203(4381), 654-656 (doi: 10.1126/science.203.4381.654)

Sisson TW and Vallance JW (2009) Frequent eruptions of Mount Rainier over the last $\sim 2,600$ years. Bull. Volcanol., 71(6), 595-618 (doi: 10.1007/s00445-008-0245-7)

Swanson DA, Malone SD and Samora BA (1992) Mount Rainier: a decade volcano. Eos, 73(16), 177-186 (doi: 10.1029/ 91EO00143)

Thelen WA, Crosson RS and Creager KC (2008) Absolute and relative locations of earthquakes at Mount St. Helens, Washington, using continuous data: implications for magmatic processes. In Sherrod DR, Scott WE and Stauffer PH eds. A volcano rekindled: the renewed eruption of Mount St. Helens, 2004-2006. US Geological Survey, Denver, CO, 71-95 (USGS Prof. Pap. 1750)

Thelen W, West M and Senyukov S (2010) Seismic characterization of the fall 2007 eruptive sequence at Bezymianny Volcano, Russia. J. Volcanol. Geotherm. Res., 194(4), 201-213 (doi: 10.1016/j.jvolgeores.2010.05.010)

Waite GP, Chouet BA and Dawson PB (2008) Eruption dynamics at Mount St. Helens imaged from broadband seismic waveforms: interaction of the shallow magmatic and hydrothermal systems. J. Geophys. Res., 113(B2), B02305 (doi: 10.1029/ 2007JB005259)

Walter F, Deichmann N and Funk M (2008) Basal icequakes during changing subglacial water pressures beneath Gornergletscher,
Switzerland. J. Glaciol., 54(186), 511-521 (doi: 10.3189/ 002214308785837110)

Weaver CS and Malone SD (1976) Mt. Saint Helens seismic events: volcanic earthquakes or glacial noises? Geophys. Res. Lett., 3(3), 197-200 (doi: 10.1029/GL003i003p00197)

Weaver CS and Malone SD (1979) Seismic evidence for discrete glacier motion at the rock-ice interface. J. Glaciol., 23(89), $171-184$

West ME, Larsen CF, Truffer M, O'Neel S and LeBlanc L (2010) Glacier microseismicity. Geology, 38(4), 319-322 (doi: 10.1130/G30606.1)

Wiens DA, Anandakrishnan S, Winberry JP and King MA (2008) Simultaneous teleseismic and geodetic observations of the stickslip motion of an Antarctic ice stream. Nature, 453(7196), 770-774 (doi: 10.1038/nature06990)

Winberry JP, Anandakrishnan S, Alley RB, Bindschadler RA and King MA (2009) Basal mechanics of ice streams: insights from the stick-slip motion of Whillans Ice Stream, West Antarctica. J. Geophys. Res., 114(F1), F01016 (doi: 10.1029/2008JF001035)

Wolf LW and Davies JN (1986) Glacier-generated earthquakes from Prince William Sound, Alaska. Bull. Seismol. Soc. Am., 76(2), 367-379

Wolf LW, Rowe CA and Horner RB (1997) Periodic seismicity near Mt. Ogden on the Alaska-British Columbia border: a case for hydrologically triggered earthquakes? Bull. Seismol. Soc. Am. 87(6), 1473-1483

MS received 26 June 2012 and accepted in revised form 14 October 2012 